\title{
Kidney ischaemia reperfusion injury in the rat: the EGTI scoring system as a valid and reliable tool for histological assessment
}

\author{
Usman Khalid ${ }^{1,2^{*}}$, Gilda Pino-Chavez ${ }^{2}$, Prabhu Nesargikar ${ }^{1,2}$, Robert H. Jenkins², Timothy Bowen², Donald J. Fraser ${ }^{2}$ and Rafael Chavez ${ }^{1,2}$
}

*Correspondence: usman.khalid@doctors.org.uk

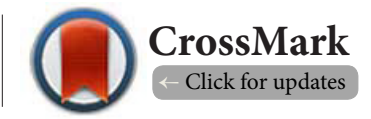

${ }^{1}$ Cardiff Transplant Unit, Department of Nephrology and Transplant Surgery, University Hospital of Wales, Heath Park, Cardiff, UK. ${ }^{2}$ Institute of Nephrology, Cardiff University, Cardiff, UK.

\begin{abstract}
Background: The widely adopted Jablonski scoring system for reporting histological damage in kidney ischaemia reperfusion injury (IRI) provides a limited score documenting the degree of necrosis within tubular cells. IRI is a complex process that involves damage to various cellular components of the renal cortex and therefore there is a need to develop a more detailed scoring system. The aims of this study were to evaluate a new comprehensive histology scoring system (comprising Endothelial, Glomerular, Tubular, and Interstitial (EGTI)components), in rat models of IRI.

Methods: Twenty-seven adult male Lewis rats underwent surgery: Left unilateral IRI (45-minutes left renal pedicle cross-clamping)(n=5); Left unilateral sham(n=5); Bilateral IRI (45-minutes bilateral renal pedicle cross-clamping)(n=9); and Bilateral sham $(\mathrm{n}=8)$. Kidney tissue was retrieved at 48 hours. Paraffin sections were examined under $\mathrm{H} \& \mathrm{E}$ staining. RNA extraction and RT-qPCR analysis were performed for acute kidney injury (AKI) markers. Serum creatinine was measured before and at 48 hours post reperfusion for the bilateral model rats.

Results: Forty-five minutes of IRI in the rat caused marked histological damage at 48 hours when compared with sham controls. This was characterized by acute tubular necrosis, endothelial cell disruption and loss, interstitial damage with inflammation, cast formation and necrosis, and glomerular capsule thickening. The EGTI scores correlated significantly with serum creatinine at 48 hours, and expression of AKI markers (NGAL and KIM-1). In addition to this, each individual component on the EGTI histology scoring system correlated significantly with serum creatinine at 48 hours, and expression of NGAL and KIM-1.

Discussion: The EGTI histology scoring system appears reliable and more informative in assessing the degree of damage observed in kidney IRI. Separate scoring parameters for Endothelial, Glomerular, Tubular, and Interstitial injury showed sensitivity to IRI, and permit quantitative analysis of injury and protection in different segments of the kidney.
\end{abstract}

Keywords: Ischaemia reperfusion injury (IRI), histology scoring system, EGTI scoring system, jablonski score

\section{Introduction}

Ischaemia reperfusion injury (IRI) is a complex pathological process characterized by initial restriction of blood supply to the organ followed by subsequent restoration of blood flow and oxygenation, and is an inevitable consequence of organ transplantation, causing significant morbidity and mortality. In kidney transplantation, IRI manifests as primary non-function and delayed graft function, leading to an increased risk of complications, acute allograft rejection and poorer long-term outcomes [1-3]. Due to the increasing donor shortage problem, expanded criteria donor organs' with the additional risk of increased IRI, are now increasingly used [4].

The pathophysiological processes involved in IRI are complex and include interactions between the endothelium, components of the immune system and cell death programs [3]. Briefly, ischaemia and resultant hypoxia cause an increase 
in vascular permeability and impaired endothelial cell barrier function. Cell death programs that consist of cell apoptosis, phagocytosis, and necrosis are activated. Apoptosis causes nuclear fragmentation, loss of mitochondrial integrity and cell shrinkage. Activation of the innate and adaptive components of the immune system, such as complement, contributes significantly to injury $[3,5]$.

In renal IRI, endothelial damage is the result of the initial ischaemia and hypoxia leading to impaired cell barrier function. This causes endothelial swelling and disruption, eventually leading to loss of endothelial integrity $[6,7]$. Tubular injury is a characteristic feature of kidney IRI since the tubules are most prone to ischaemic damage, and therefore potentially reversible acute tubular necrosis is a hallmark of kidney injury. Specifically, in IRI, hypoxia results in formation of plasma membrane blebs and loss of brush border membrane leading to loss of polarity and integrity of tight junctions. Cast formation occurs secondary to cell death and sloughing. As a result, cast formation and other debris lead to tubular obstruction. These changes, along with tubular necrosis, signify extensive tubular damage [8]. Interstitial damage is also seen in acute kidney injury, but may also result from chronic and progressive damage of varied aetiology. Inflammation, haemorrhage and necrosis are the hallmarks of acute ischaemic damage to the tubulo-interstitium [9]. Thickening of Bowman's capsule, retraction of the glomerular tuft and, in severe cases, glomerular fibrosis are the histological features of ischaemic glomerular damage [10].

Full and comprehensive documentation of these complex features of acute kidney injury is important, to facilitate determination of prognosis following biopsy, and to enable mechanistic studies in this area. The widely adopted 'gold standard'scoring system for reporting histological damage in kidney injury is the Jablonski scoring system [11]. This simple system is designed to give a rapid and objective assessment of kidney injury. In reality, however, it provides a limited score documenting predominantly the degree of necrosis within tubular cells only, ranging from 0 signifying 'no damage', to 4 'necrosis affecting all 3 segments of the proximal convoluted tubule'. It does not provide an assessment of the damage seen within the other cellular components, such as endothelial and glomerular cells. The Jablonski scoring system was originally described following a prolonged recovery period after ischaemic injury, and includes features of recovery (e.g. Tubular cell mitoses) that may not be evident in the typical recovery periods used experimentally, or in clinical samples.

The damage seen in IRI is not limited to tubular cells and includes also endothelial, glomerular and interstitial changes. Exclusive focus on the proximal tubule removes the possibility of detection of varied propensity for injury in these compartments, depending on clinical context and/or experimental therapeutic approach applied. There is a need, therefore, to develop a more detailed scoring system that is simple, reliable and more informative regarding the degree of tissue damage to the various cellular components of the kidney.

Here, we present the EGTI (Endothelial, Glomerular, Tubular, Interstitial) scoring system, and its analyisis in rat models of acute IRI, in comparison with the Jablonski scoring system. In addition, scores were correlated with established acute kidney injury markers neutrophil gelatinase-associated lipocalin (NGAL) and kidney injury molecule 1 (KIM-1), together with serum creatinine as a measure of excretory kidney function, in order to establish their inter-relationships in this model.

\section{Methods \\ Rat models of IRI}

Adult (8 to 12 week old) male Lewis rats weighing $180-220 \mathrm{~g}$ were used (Harlan Laboratories, UK). The rats were given a 7-day period of acclimatisation to their new environment and were housed and handled according to the local institutional policies and procedures licenced by the Home Office. Analgesia was provided 24 hours pre-op throughout until the time of retrieval in the form of $200 \mathrm{mcg}$ of buprenorphine dissolved in $500 \mathrm{ml}$ of drinking water. The animals were anaesthetized using Isoflurane and midline laparotomy incisions were made.

Two rat models were used: unilateral IRI and bilateral IRI. In the unilateral model, the left renal pedicle was identified and clamped for 45 minutes using a vascular clip (IRI group). In the bilateral model, both kidneys were identified and their pedicles simultaneously clamped for 45 minutes using vascular clips (IRI group). In both models, the kidneys were visually assessed for both ischaemia upon clamping and subsequent reperfusion upon release of the clamp. Sham controls underwent the same operation without the renal pedicle clamping. During the ischaemic period the abdominal cavity was covered with saline-soaked gauze. The kidneys were retrieved at 48 hours following terminal anaesthesia.

\section{Histology}

Kidney tissue was embedded in paraffin and $5 \mu \mathrm{m}$ tissue sections obtained for Haemotoxylin and Eosin (H\&E) staining. Histological damage was assessed by an experienced histopathologist blinded as to group allocation (sham versus IRI) and quantified using the EGTI scoring system devised specifically for animal research on kidney tissue in the context of injury (Table 1). The scoring system consists of histological damage in 4 individual components: Endothelial, Glomerular, Tubular, and Interstitial. The scoring was performed in both the preserved and damaged parts of the renal cortex. The Jablonski score was also recorded.

\section{RT-qPCR}

Total RNA was extracted using TRIzol reagent (Life technologies) according to manufacturer's instructions. Generation of cDNA was carried out using the High Capacity Reverse Transcription Kit (Life Technologies) with random primers, and RT-qPCR was performed on a ViiA7 Fast Real-Time PCR System (Life Technologies). NGAL and KIM-1 were quantified using 
Khalid et al. Journal of Histology \& Histopathology 2016, http://www.hoajonline.com/journals/pdf/2055-091X-3-1.pdf

Table 1. The EGTI histology scoring system.

\begin{tabular}{|c|c|c|}
\hline Tissue type & Damage & Score \\
\hline \multirow[t]{5}{*}{ Tubular } & No damage & 0 \\
\hline & $\begin{array}{l}\text { Loss of Brush Border (BB) in less than } 25 \% \text { of } \\
\text { tubular cells. Integrity of basal membrane. }\end{array}$ & 1 \\
\hline & $\begin{array}{l}\text { Loss of BB in more than } 25 \% \text { of tubular cells, } \\
\text { Thickened basal membrane }\end{array}$ & 2 \\
\hline & $\begin{array}{l}\text { (Plus) Inflammation, Cast formation, } \\
\text { Necrosis up to } 60 \% \text { of tubular cells }\end{array}$ & 3 \\
\hline & $\begin{array}{l}\text { (Plus) Necrosis in more than } 60 \% \text { of tubular } \\
\text { cells }\end{array}$ & 4 \\
\hline \multirow[t]{4}{*}{ Endothelial } & No damage & 0 \\
\hline & Endothelial swelling & 1 \\
\hline & Endothelial disruption & 2 \\
\hline & Endothelial loss & 3 \\
\hline \multirow[t]{4}{*}{ Glomerular } & No damage & 0 \\
\hline & Thickening of Bowman capsule & 1 \\
\hline & Retraction of glomerular tuft & 2 \\
\hline & Glomerular fibrosis & 3 \\
\hline \multirow{5}{*}{$\begin{array}{l}\text { Tubulo/ } \\
\text { Interstitial }\end{array}$} & No damage & 0 \\
\hline & $\begin{array}{l}\text { Inflammation, haemorrhage in less than } 25 \% \\
\text { of tissue }\end{array}$ & 1 \\
\hline & (Plus) necrosis in less than $25 \%$ of tissue & 2 \\
\hline & Necrosis up to $60 \%$ & 3 \\
\hline & Necrosis more than $60 \%$ & 4 \\
\hline
\end{tabular}

the POWER SYBR ${ }^{\circledR}$ GREEN PCR Master Mix (Life technologies) with gene-specific primers and normalized to house keeping gene GAPDH. Changes in gene expression were analysed using the $2^{-\mathrm{DDCT}}$ method [12].

Primers' sequences used were:

GAPDH (forward, 5'-CCTCTGACTTCAACAGCGACAC-3'; reverse, $5^{\prime}$-TGTCATACCAGGAAATGAGCTTGA-3'),

NGAL (forward, 5'-GGGCTGTCCGATGAACTGAA-3';

reverse, 5'-CATTGGTCGGTGGGAACAGA-3'),

KIM-1 (forward, 5'-CGGCTAACCAGAGTGACTTGT-3';

reverse, 5'-TACAGAGCCTGGAAGAAGCAG-3'),

\section{Serum creatinine}

Serum creatinine in $\mathrm{mmol} / \mathrm{l}$ was measured using the Jaffe reaction before operation and at time of retrieval in the bilateral IRI model.

\section{Statistical analysis}

Statistical analyses were performed using GraphPad Prism v6 software. Data were expressed as mean \pm SEM or median (and range) and assessed for statistical significance by unpaired Student's $t$ test or Mann Whitney U test. The EGTI Histology score and the Jablonski score were correlated with serum ceatinine, NGAL and KIM-1. Correlation analysis was reported with significance levels as indicated, where appropriate, in the figures provided: ${ }^{*} p<0.05,{ }^{* *} p<0.01,{ }^{* * *} p<0.001$.

\section{Results \\ Histology}

Ten rats were used for the unilateral model ( $5 \mathrm{IRI}, 5$ sham) and 17 for the bilateral model ( 9 IRI and 8 sham). Forty-five minutes of unilateral and bilateral IRI in the rat caused marked histological damage at 48 hours when compared with sham controls.

Figures $1 \mathrm{~A}-1 \mathrm{C}$ show normal appearance of the renal cortex in a Sham rat. Figure $1 \mathrm{~A}$ shows that the brush border of the tubular cells is intact with no thickening of the basal membrane. No inflammation or necrosis is seen (Tubular score 0 ). There is no visible interstitium signifying no damage/abnormality within the interstitial compartment (Interstitial score 0). Figure 1B shows a uniform endothelium with no swelling or disruption of the endothelial cells (Endothelial score 0 ). Figure $1 \mathrm{C}$ shows an intact glomerulus with thin walled Bowman's capsule and no tuft retraction (Glomerular score 0 ).

Figures 1D-1F show varying degrees of damage of the renal cortex in 45-minute bilateral IRI rats. Figure 1D shows inflammation and haemorrhage within the interstitium which is present in less than $25 \%$ of the tissue without any evidence of necrosis (Interstitial score 1). Figure 1E shows thickened basal membrane of the tubular cells with loss of the brush border in more than $25 \%$ of the tubular cells, without the presence of cast formation or necrosis (Tubular score 2). Figure 1F shows a glomerulus with evidence of thickened Bowman's capsule (Glomerular score 1), and glomerular tuft retraction (Glomerular score 2).

Figures 1G-1I show varying degrees of damage of the renal cortex in 45 -minute unilateral IRI rats. Figure $1 \mathrm{G}$ shows inflammation and haemorrhage within the interstitial compartment, with necrosis in up to $60 \%$ of the cells (Interstitial score 3). Figure $1 \mathrm{H}$ shows complete necrosis in tubular and interstitial cellular compartments (Tubular score 4, Interstitial score 4). Figure 11 shows evidence of inflammation and cast formation within the tubules with evidence of necrosis in up to $60 \%$ of tubular cells (Tubular score 3 ), and endothelial cell disruption and loss (Endothelial score 3).

Figure 2 shows mild damage of the renal cortex in a 45-minute bilateral IRI rat. There is endothelial swelling of the capillaries (A) and the vessel (B) without any disruption (Endothelial score 1).

\section{Unilateral IRI}

The median (and range) EGTI histology score was 10 (8-11) in the IRI group compared to 0 (0-1) in the sham group $(p=0.0079)$. The mRNA expression of KIM-1 and NGAL was increased 300 -fold and 30 -fold in the IRI group respectively compared to sham group $(p<0.0001)[13]$.

\section{Bilateral IRI}

The median (and range) EGTI histology score was 8 (6-9) in the 

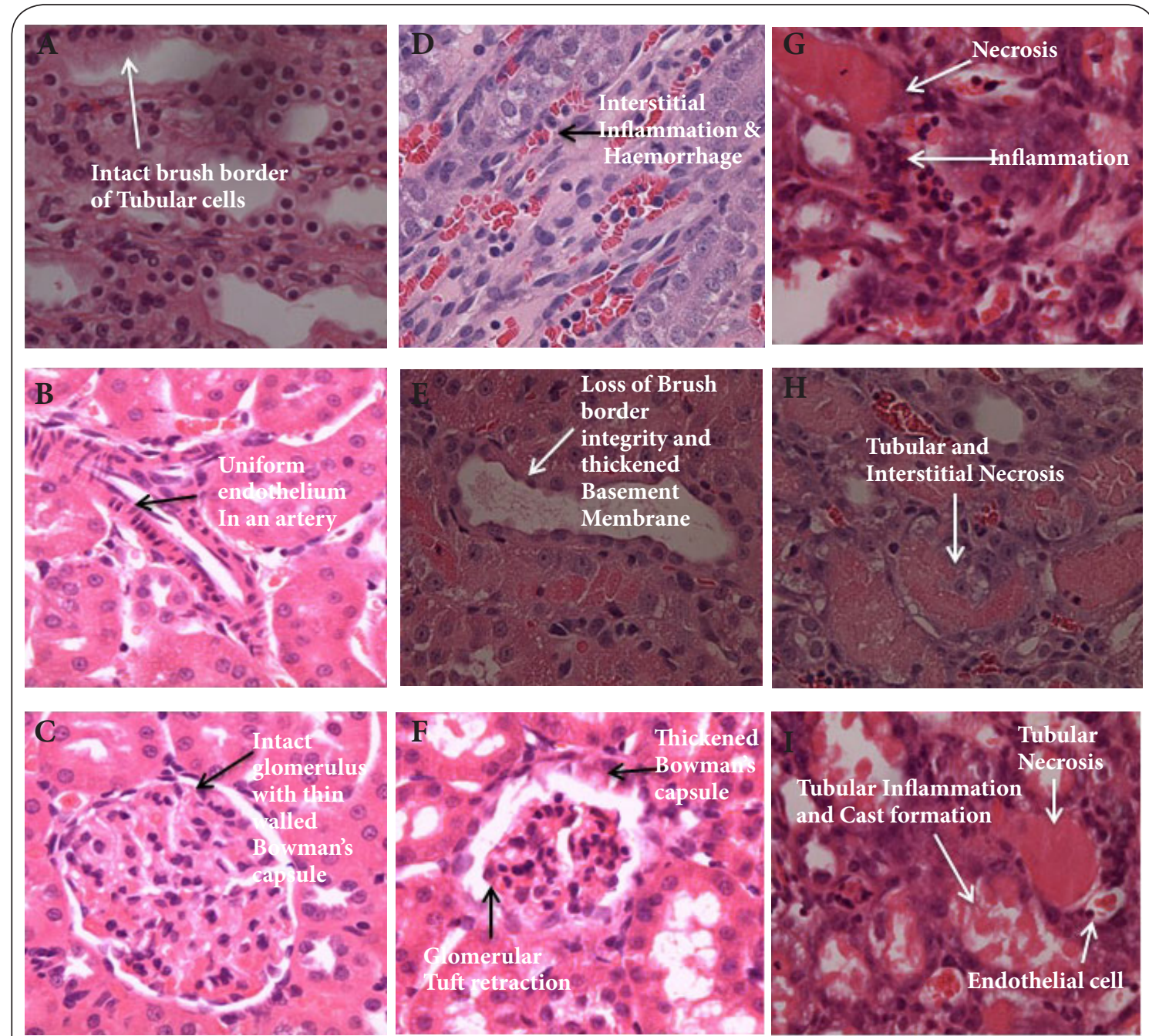

Figure 1. Histological images of rat renal cortex sections.

Renal cortex H\&E (x400) paraffin sections, from sham and 45-minute IRI in rats, at 48 hours after reperfusion (Bilateral sham $n=8$, Bilateral IRI $n=9$, Unilateral sham $n=5$, Unilateral IRI $n=5$ ) were assessed for Endothelial, Tubular, Glomerular and Interstitial cell damage. (A-C) Normal appearance of renal cortex ina sham rat. (D-F) Mild to moderate damage of the renal cortex in 45-minute bilateral IRI rats. (G-I) Moderate to significant damage of the renal cortex in unilateral 45-minute IRI rats.
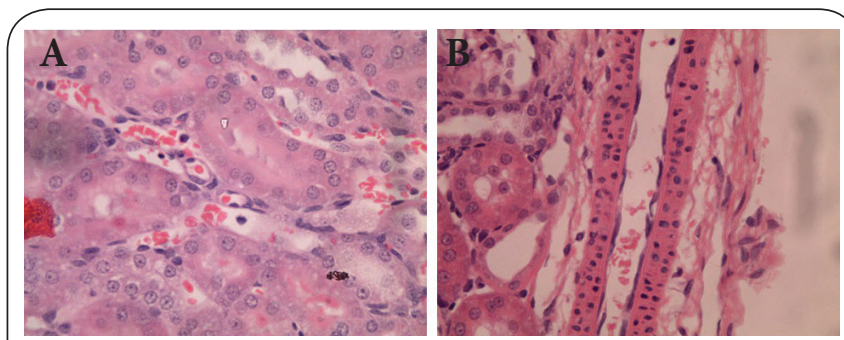

Figure 2. Histological images of endothelial cell swelling in rat renal cortex sections.

Renal cortex H\&E (x400) paraffin sections, from sham and 45 -minute IRI in rats, at 48 hours after reperfusion (Bilateral sham $n=8$, Bilateral IRI $n=9$, Unilateral sham $n=5$, Unilateral IRI n=5) were assessed for Endothelial, Tubular, Glomerular and Interstitial cell damage. Mild damage of the renal cortex in a 45 -minute IRI rat.
IRI group compared to $0(0-2)$ in the sham group $(p<0.0001)$. Mean serum creatinine at 48 hours was $76.63( \pm 13.36) \mathrm{mmol} / \mathrm{l}$ in the IRI group compared with $31.90( \pm 0.25) \mathrm{mmol} / \mathrm{l}$ in the sham group $(p=0.0067)$. The mRNA expression of KIM- 1 and NGAL was increased 150-fold and 14-fold in the IRI group respectively $(p<0.0001)$ (Figure 3 ). The individual components of the EGTI score were also significantly higher in the IRI group compared with sham (Figure 4).

\section{Correlation of EGTI histology scores and Jablonski scores with serum creatinine, and AKI markers}

The EGTI and Jablonski scores both correlated significantly with serum creatinine at 48 hours, and expression of NGAL and KIM-1 (Figure 5). This suggests that both the EGTI score and the Jablonski score are highly predictive of kidney function 

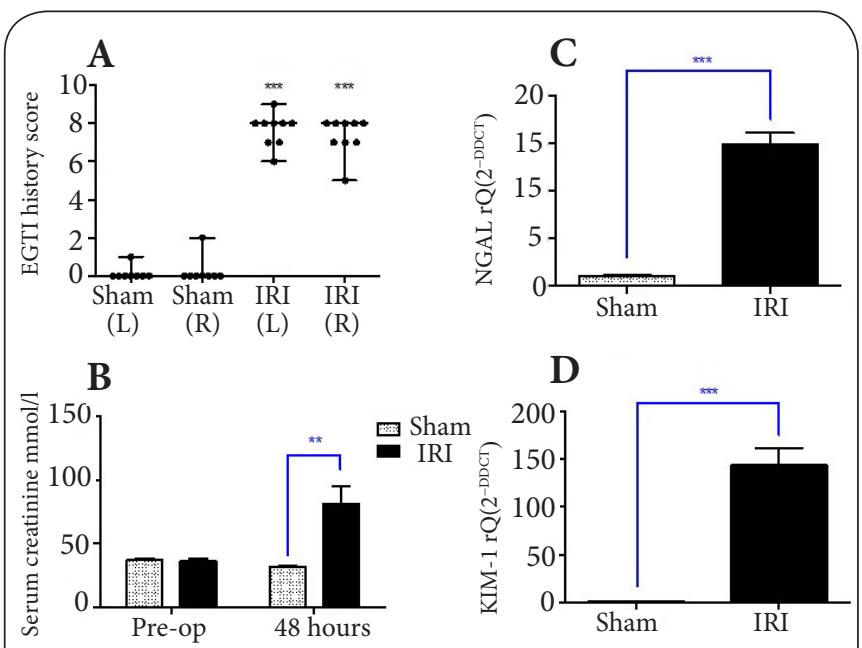

Figure 3. Effect of bilateral IRI on EGTIscore, serum creatinine and expression of NGAL and KIM-1.

(A) Renal cortex sections from sham and 45-minute bilateral IRI in rats at 48 hours after reperfusion were stained with $\mathrm{H} \& \mathrm{E}$ and assessed using a comprehensive scoring system comprising of Endothelial, Glomerular, Tubular, and Interstitial cell damage (Sham $n=8$, IRI $n=9$ ). Histology scores are plotted as median and range, ${ }^{* *} \mathrm{p}<0.0001$. (B) Serum creatinine was measured pre-op and at 48 hours and is plotted as mean $\pm S E M,{ }^{*} p=0.0077$. (C and D) RT-qPCR analysis of KIM-1 and NGAL was performed. Expression is normalized to GAPDH and plotted as mean \pm SEM, ${ }^{* * *} \mathrm{p}<0.0001$.
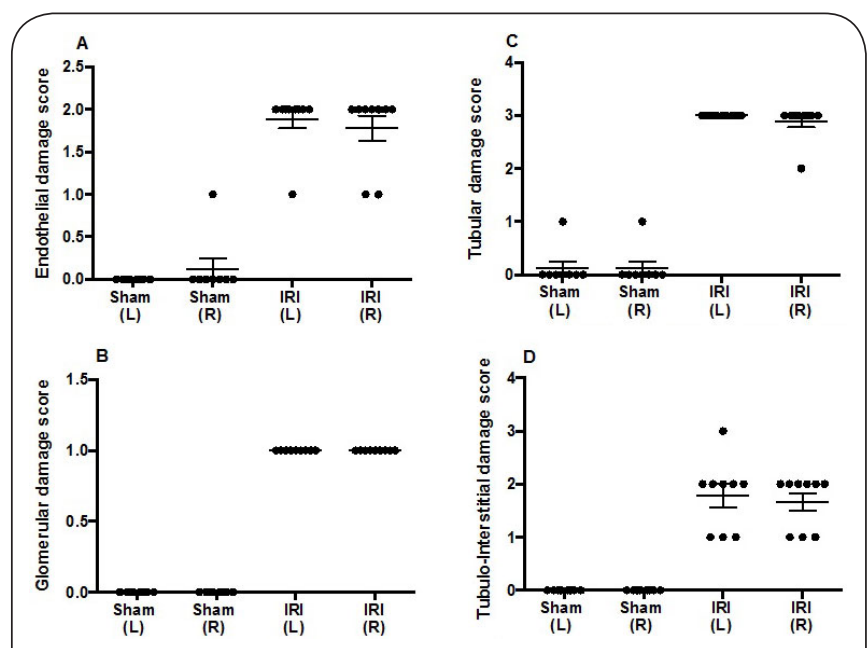

Figure 4. Effect of bilateral IRI on Endothelial, Tubular, Glomerular and Tubulo-Interstitial damages scores. Renal cortex sections from sham and 45-minute bilateral IRI in rats at 48 hours after reperfusion were stained with $\mathrm{H} \& \mathrm{E}$ and assessed using a comprehensive scoring system comprising of Endothelial, Glomerular, Tubular, and Interstitial cell damage (Sham $n=8$, IRI $n=9$ ). Individual cellular component scores are plotted as median and range for Tubular (A), Endothelial (B), Glomerular (C) TubuloInterstitial (D) components. and structural damage.

In addition to this, the association between each component on the EGTI histology scoring system and serum creatinine at 48 hours, and expression of NGAL and KIM-1 was examined using univariate logistic regression analyses. Tubular, endothelial, glomerular, and tubulo-interstitial components were independently associated with serum creatinine at 48 hours $(p<0.05)$, and NGAL and KIM-1 $(p<0.0001)$.

\section{Discussion}

This study used rat models of acute IRI to evaluate a new scoring system to document changes in the histological architecture of the renal cortex, established acute kidney injury markers and renal function.

The rat models used in this study are well-established in vivo models of acute kidney injury $[\mathbf{1 4 , 1 5}$. Adult male rats are known to be more susceptible to injury, and so consistent sex selection is an important component [16]. The 45-minutes of cross-clamping of the renal pedicle produces significant but non-fatal, and potentially reversible, injury. The 48-hour reperfusion period is ample to assess the effects of a treatment modality on injury in the acute setting [17], and previous reports have shown that the 45-minute model of IRI used here allows robust and reproducible evaluation of treatment effects on IRI $[18,19]$. In kidney transplantation most damage occurs in the acute setting, therefore the model used in this study was chosen to reflect this. To ensure that the newly developed scoring system was robust in the presence of functional as well as structural changes as a consequence of IRI, bilateral as well as unilateral IRI models were employed.

The majority of studies investigating kidney IRI report the histological damage according to Jablonski's acute tubular necrosis score [11]. This score is based solely on damage within the tubular cells. It does not document any damage seen to the other cellular components within the renal cortex. Tubular injury is arguably the most characteristic feature of kidney IRI but damage to other structural renal components is also important. The Jablonski scoring system is designed to give a rapid and objective assessment of kidney tubular injury, and is relatively straightforward to use. This system was originally described in a rat model of ischaemia followed by 7 or 14 days of reperfusion [11]. Such a prolonged reperfusion period results in the development of time-dependent morphological features in kidney tissue. For example, a score of ' 1 ' includes reference to the presence of mitoses. Mitoses are evident in the presence of tubular cell regeneration, which does not occur in acute models of IRI such as those used in the present study. For acute IRI models, the Jablonski scoring system must therefore be modified to exclude this mitotic criterion. Another significant limitation of the Jablonski system is the absence of brush border observations. One of the first tubular cell changes seen following iscahemic injury is loss of the brush border membrane, prior to cast formation or necrosis. 


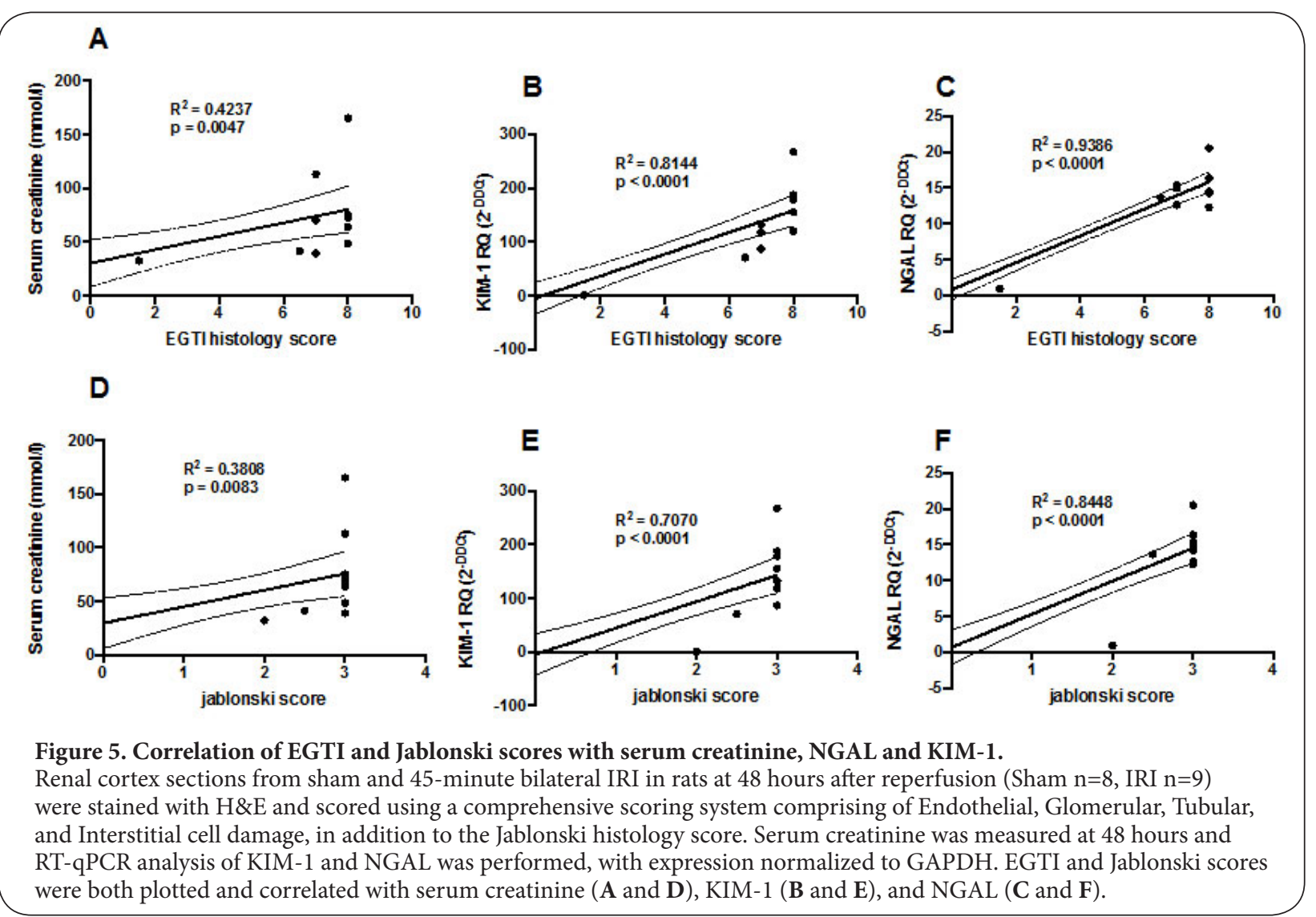

Kidney IRI is a complex pathophysiological process that causes structural damage to tubular, endothelial, glomerular and tubulo-interstitial cells. Loss of endothelial cell integrity, acute tubular necrosis, tubulo-interstitial damage and glomerular ischaemic damage are all hallmarks of kidney IRI that are important to document fully and comprehensively. It is evident from Figures 1D-1I that there is some variation in IRI animals in terms of the damage to various cellular components. This supports further the need for a histology scoring system that reports damage to all of these cellular components.

KIM-1 and NGAL were selected as accurate, robust and reliable biomarkers of acute kidney injury $[14,20,21]$. It is evident from the histological and acute kidney injury marker changes that the models of IRI used in this study led to significant injury to the kidney. Serum creatinine was selected as a marker of kidney function in the bilateral IRI model. It is the most widely used marker of excretory kidney function, reliably estimating glomerular filtration rate in clinical practice [22]. In this study, changes in serum creatinine between bilateral sham and bilateral IRI rats suggest that this model of acute injury is robust.

The EGTI histology scoring system proposed in this study correlated significantly with established AKI markers and serum creatinine, demonstrating its validity, reliability and sensitivity. Moreover, by reporting changes seen within all of the cellular components of the renal cortex, our new system offers a greater insight into the severity and range of damage than the Jablonski system. Similarly to the EGTI scores, the Jablonski scores correlated significantly with serum creatinine, NGAL, and KIM-1, although the correlation was slightly less pronounced.

\section{Conclusion}

The EGTI histology scoring system described in this paper is a reliable, sensitive and valid tool to assess the degree of damage observed in kidney IRI. It is also more comprehensive than the widely used Jablonski scoring system.

\section{Competing interests}

The authors declare that they have no competing interests.

\section{Authors' contributions}

\begin{tabular}{|l|c|c|c|c|c|c|c|}
\hline Authors' contributions & UK & GPC & PN & RJ & TB & DF & RC \\
\hline Research concept and design & $\checkmark$ & $\checkmark$ & -- & -- & -- & $\checkmark$ & $\checkmark$ \\
\hline Collection and/or assembly of data & $\checkmark$ & $\checkmark$ & $\checkmark$ & $\checkmark$ & -- & -- & -- \\
\hline Data analysis and interpretation & $\checkmark$ & $\checkmark$ & $\checkmark$ & $\checkmark$ & $\checkmark$ & $\checkmark$ & $\checkmark$ \\
\hline Writing the article & $\checkmark$ & -- & -- & -- & -- & -- & -- \\
\hline Critical revision of the article & $\checkmark$ & $\checkmark$ & $\checkmark$ & $\checkmark$ & $\checkmark$ & $\checkmark$ & $\checkmark$ \\
\hline Final approval of article & $\checkmark$ & $\checkmark$ & $\checkmark$ & $\checkmark$ & $\checkmark$ & $\checkmark$ & $\checkmark$ \\
\hline Statistical analysis & $\checkmark$ & -- & -- & $\checkmark$ & -- & -- & -- \\
\hline
\end{tabular}




\section{Acknowledgement and funding}

We would like to thank Kidney Wales Foundation grant (for funding this project) and Department of Pathology, University Hospital of Wales, Cardiff (for their help with processing of kidney tissue specimens in formalin).

\section{Publication history}

Editors: Paola Castrogiovanni, University of Catania, Italy. Lingyan Wang, Oregon Health \& Science University, Portland. EIC: Gaetano Giuseppe Magro, University of Catania, Italia. Received: 23-Oct-2015 Final Revised: 17-Dec-2015

Accepted: 24-Dec-2015 Published: 04-Jan-2015

\section{References}

1. Ojo AO, Wolfe RA, Held PJ, Port FK and Schmouder RL. Delayed graft function: risk factors and implications for renal allograft survival. Transplantation. 1997; 63:968-74. | Article I PubMed

2. Perico N, Cattaneo D, Sayegh MH and Remuzzi G. Delayed graft function in kidney transplantation. Lancet. 2004; 364:1814-27. | Article | PubMed

3. Eltzschig HK and Eckle T. Ischemia and reperfusion--from mechanism to translation. Nat Med. 2011; 17:1391-401. | Article | PubMed Absract | PubMed Full Text

4. Transplant NBa. NHS Blood and Transplant Organ Donation and Transplantation Activity Report in the UK. 2014-15. I Pdf

5. Godwin JG, Ge X, Stephan K, Jurisch A, Tullius SG and lacomini J. Identification of a microRNA signature of renal ischemia reperfusion injury. Proc Natl Acad Sci U S A. 2010; 107:14339-44. I Article I PubMed Absract | PubMed Full Text

6. Bonventre JV and Yang L. Cellular pathophysiology of ischemic acute kidney injury. J Clin Invest. 2011; 121:4210-21. I Article I PubMed Absract | PubMed Full Text

7. Rabelink TJ, de Boer HC and van Zonneveld AJ. Endothelial activation and circulating markers of endothelial activation in kidney disease. Nat Rev Nephrol. 2010; 6:404-14. | Article | PubMed

8. Patschan D, Patschan S and Muller GA. Inflammation and microvasculopathy in renal ischemia reperfusion injury. J Transplant. 2012; 2012:764154. | Article | PubMed Absract | PubMed Full Text

9. Bonventre JV and Weinberg JM. Recent advances in the pathophysiology of ischemic acute renal failure. J Am Soc Nephrol. 2003; 14:2199-210. I Article I PubMed

10. Munshi R, Hsu C and Himmelfarb J. Advances in understanding ischemic acute kidney injury. BMC Med. 2011; 9:11. | Article | PubMed Absract | PubMed Full Text

11. Jablonski P, Howden BO, Rae DA, Birrell CS, Marshall VC and Tange J. An experimental model for assessment of renal recovery from warm ischemia. Transplantation. 1983; 35:198-204. | Article | PubMed

12. Livak KJ and Schmittgen TD. Analysis of relative gene expression data using real-time quantitative PCR and the 2(-Delta Delta C(T)) Method. Methods. 2001; 25:402-8. | Article | PubMed

13. Khalid U, Jenkins R, Pino-Chavez G, Bowen T, Fraser D and Chavez R. A Localized Ischemic Preconditioning Regimen Increases Tumor Necrosis $\alpha$ Expression in a Rat Model of Kidney Ischemia-Reperfusion Injury. Experimental and Clinical Transplantation. 2015.

14. Mishra J, Ma Q, Prada A, Mitsnefes M, Zahedi K, Yang J, Barasch J and Devarajan P. Identification of neutrophil gelatinase-associated lipocalin as a novel early urinary biomarker for ischemic renal injury. J Am Soc Nephrol. 2003; 14:2534-43. I Article I PubMed

15. Kato J, Nakayama M, Zhu WJ, Yokoo T and Ito S. Ischemia/reperfusion of unilateral kidney exaggerates aging-induced damage to the heart and contralateral kidney. Nephron Exp Nephrol. 2014; 126:183-90. | Article | PubMed

16. Park KM, Kim JI, Ahn Y, Bonventre AJ and Bonventre JV. Testosterone is responsible for enhanced susceptibility of males to ischemic renal injury. J Biol Chem. 2004; 279:52282-92. I Article I PubMed
17. Dokuyucu R, Demir T, Yumrutas O, Erbagci AB, Orkmez M, Bahar AY, Bayraktar R, Bozgeyik I, Kaplan DS, Cengiz B and Bagci BC. The role of hepcidin and its related genes (BMP6, GDF-15, and HJV) in rats exposed to ischemia and reperfusion. Turk J Med Sci. 2014; 44:576-81. | Pdf | PubMed

18. Delbridge MS, Shrestha BM, Raftery AT, El Nahas AM and Haylor JL. The effect of body temperature in a rat model of renal ischemia-reperfusion injury. Transplant Proc. 2007; 39:2983-5. I Article I PubMed

19. Wystrychowski W, Wystrychowski G, Zukowska-Szczechowska E, Obuchowicz E, Grzeszczak W, Wiecek A and Wystrychowski A. Nephroprotective effect of pentoxifylline in renal ischemia-reperfusion in rat depends on the timing of its administration. Transplant Proc. 2014; 46:2555-7. | Article | PubMed

20. Vaidya VS, Ozer JS, Dieterle F, Collings FB, Ramirez V, Troth S, Muniappa N, Thudium D, Gerhold D, Holder DJ, Bobadilla NA, Marrer E, Perentes E, Cordier A, Vonderscher J, Maurer G, Goering PL, Sistare FD and Bonventre JV. Kidney injury molecule-1 outperforms traditional biomarkers of kidney injury in preclinical biomarker qualification studies. Nat Biotechnol. 2010; 28:478-85. | Article | PubMed Absract | PubMed Full Text

21. Mishra J, Dent C, Tarabishi R, Mitsnefes MM, Ma Q, Kelly C, Ruff SM Zahedi K, Shao M, Bean J, Mori K, Barasch J and Devarajan P. Neutrophil gelatinase-associated lipocalin (NGAL) as a biomarker for acute renal injury after cardiac surgery. Lancet. 2005; 365:1231-8. | Article | PubMed

22. Suzuki Y, Matsushita K, Yoshida T, Sawabe Y and Nomura F. [Clinical validity of renal function markers including serum cystatin $\mathrm{C}$ on chronic kidney disease classification]. Rinsho Byori. 2011; 59:345-51. | Article | PubMed

\section{Citation:}

Khalid U, Pino-Chavez G, Nesargikar P, Jenkins RH, Bowen T, Fraser DJ and Chavez R. Kidney ischaemia reperfusion injury in the rat: the EGTI scoring system as a valid and reliable tool for histological assessment. J Histol Histopathol. 2016; 3:1. http://dx.doi.org/10.7243/2055-091X-3-1 